\title{
Development of Rose Model for Hybrid Renewable Energy Generation and Analysis of Carbon Foot Printing QOS Parameters
}

\author{
Manjusha Sham Patil, Anwar Mubarak Mulla
}

\begin{abstract}
The risk presented by world-wide weather transformation is known and so the government panel about weather transformation prompts that guidelines need to be consider limiting world-wide median temperature boost. I expect effective strategies meant for the statistic and administration of GHG exhausts for aim for positioning and determining the accomplishment of climate change minimization activities. 'Carbon footprints' are progressively being acknowledged as an important signal in the arena of GHG and carbon exhausts supervision. During COVID-19 pandemic the GHG percentage dropped considerably for a moment worldwide, but there is an immense need of lowering carbon foot printing with development of new hybrid renewable energy sources. This paper presents the innovative development in the same direction by development of rose model for automation of energy plants to reach its installed capacity with identification of MPPT along with optimum ratio ofdemand-supply. Paper also presents the analysis of proposed developments.
\end{abstract}

Keyword: Hybrid Renewable Energy Sources, Carbon Footprints, Rose Model, MPPT, QOS Parameter Analysis

\section{INTRODUCTION}

The terminology carbon footprint has turned into a typically accepted term, commonly accustomed to summarize the strategy concerning a specified level of GHG exhausts to a specific process, system or perhaps inhabitants $[1,2,3]$. The terminology is additionally utilized synonymously by various conditions just like 'carbon accounting' or maybe 'carbon inventory'. The usage of the terminology has been operated typically through information, authorities, industry as well as, nongovernmental institutions, alluring the significance of organization, clients and so policy designers, nonetheless theterminology has merely lately been implemented through the informative network, just where efforts has usually aimed on life cycle analysis (LCA) [4,5,6,7]. As a consequence, previous authors advise that certainly, there is dilemma as well as little accord with what the terminology essentially represents or perhaps which the procedure dimensions.

Manuscript received on September 06, 2021.

Revised Manuscript received on September 13, 2021.

Manuscript published on September 30, 2021.

*Correspondence Author

Mrs. Manjusha Sham Patil*, PhD Scholar, Department of Electrical Engineering, Shri Jagdishprasad Jhabarmal Tibrewala University, Churela (Rajasthan), India.

Dr. Anwar. Mubarak, Department of Electrical Engineering, Shri Jagdishprasad Jhabarmal Tibrewala University, Churela (Rajasthan), India.

(c) The Authors. Published by Blue Eyes Intelligence Engineering and Sciences Publication (BEIESP). This is an open access article under the CC BY-NC-ND license (http://creativecommons.org/licenses/by-nc-nd/4.0/)
Existing research has revealed that the aspect of statistics complications simply cannot be utilized to rationalize exemption of exhausts, proclaiming that statistics access for exhausts monitoring will strengthen with time as well as, an important signal need to incorporate all GHGs $[8,9]$.Especially in cases where one takes the carbon footprint, seeing that a signal meant for most GHGs, it is a work in solitude can allow an unreliable impression of the entire impression in several cases. For being nearly effective, a carbon footprint needs to be a signal concerning the anthropogenic impact among a termed technique to environment transformation [10, 11]. Employed in separation, it can crash to reflect on geographical affect categorizations such as land-use, caused in 'burden shifting'; as an illustration, bio-fuels are beneficial to precious energy sources in the event that viewed as relating to environment influence, however, this breaks down to reflect on the influences on area [12]. A carbon footprint is a signal among the contributions formed to weather transformation through a system, processes as well as populace, as an alternative to a total LCA, so it needs to be processed as such as a decision supporting application, preferably than a decision developing application [13,14]. The approach that carbon footprints are proclaimed to scheme decision producers, providers as well as, individuals is an essential condition. Demonstration as well as , manifestation of carbon footprints is an essential condition in the production concerning a sensible as well as, workable carbon footprint classification [15]. The more general unit for outcomes is CO2 e, estimated implementing the GWP. The GWP indication is usually employed in LCA to point out promising weather change influences. It is a determination of the severity to which a presented GHG provides to world-wide warming [16].Sometimes the green energy systems are viewed as probable electricity producing resources, a setback of the energy source possibilities is the irregular quality and so dependence upon climate as well as, whether circumstances [17]. This concern triggers the point that green power formulation cannot adhere to the effectiveness requirements concerning the load at every time. This kind of challenge interrelated by the diverse aspect of such assets may be resolved through combining the outlined solutions in an acceptable hybrid conjunction that features the potential to boost the model efficacy and so the energy resource stability [18]. Consequently, the sustainable energy transmission in upcoming sustainable organizations may easily be boosted. This paper hence targeted to develop and analyze rose model for periodical utilization of renewable energy sources.

Published By:

Blue Eyes Intelligence Engineering

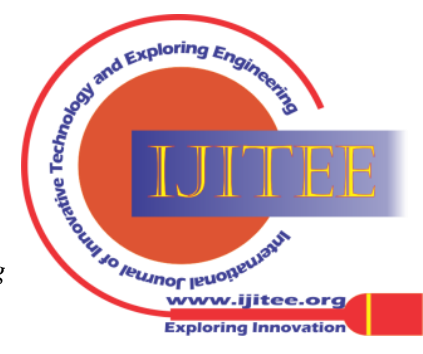


The analysis conducted for Maharashtra region for hybrid rotational execution of proposed model.

\section{LITERATURE REVIEW}

The pattern of the hybrid sustainable energy source units can be assessed simply by its life-time expense as well as emission. The life-time expense commonly comprises several additional factors in addition to the functional expense. Such factors incorporate the capitulars expense as well as the service expense, mutually introduced to as the "permanent expense"

[19]. In computation of the life-time expense, variations in the economic importanceanticipated to time frame needs to be undertaken. Consequently, the maximum hybrid model setup attempts a collaboration of turbine categories as well as, features which usually effect in the minimum life-time expense as well as, emission [20]. Within all conceivable hybrid program designs that are suitably sent, the configuration by the minimum Net Present Value is proclaimed as the "optimum disposition" or perhaps the ideal pattern [21]. To eliminate such concerns an innovative (HRESs) has surfaced. HRES is a collaboration of sustainable, typical energy methods, and so electric storages to satisfy the load regionally in both grids associated and mode in remote as well as outlying sectors. In this setting, because of unsure aspect of sustainable methods, typical energy solutions as well as energy storages might be utilized as the backup information pertaining to them. Actually, within the durations in which intern the outcome of sustainable solutions is certainly not a sufficient amount of the load, left over portion of the load may be produced through the backup assets [22]. Upon the different side, whenever the sustainable methods have an excessive era, the excessive energy can be utilized through the energy storages. Subsequently, HRESs possess more consistency than solely sustainable energy systems instandalone mode [23]. Among the beneficial concerns HRES is optimum scheduling of its element, e.g., quantity of Wind Turbines (WTs), PhotoVoltaic (PV) arrays as well as potential of generator as well as conversion so that the intent capabilities are strengthened and so all limitations are convinced [24]. Meant for this intent, most software as well as improvement strategies are recommended in the manuscripts. Presently there are relevant articles which have assessed remarkable setting up as well as performance solutions of HRES by varied points of views. HOMER has broadly been utilized in former sustainable energy program analyses capturing space in the studies [25,26]. Simultaneously grid-parallel as well as stand-alone units have been explored. Rather than the simultaneous collaboration of alternative energy resources and so typical units just like diesel turbines has also been regarded in various researches. The controlled annealing is a typical improvement procedure for handling combinatorial improvement concerns. A solid in a temperature tub is warmed up through elevating the temperatures concerning the temperature tub and therefore cooled off using gradually lessening the warmth among the heat bath in the annealing approach [27]. Multi-objective improvement issue is a further procedure which usually been utilized to model an HRES. Through pondering inconsistent pursuits a set of affected alternatives, primarily seen as non-dominated, nonapproach, particularly Hybrid Renewable Energy Systems standalone modalities. HRESs are employed in a separate

inferior or perhaps Pareto-optimal alternatives can be provided [28]. Author used a power Pareto evolutionary algorithm (PPEA) to decide the optimum proportions and maximum ability administration technique guidelines for an HRES by goal of reducing ultimate charge, unmet fill, as well as gasoline release together [29]. Author likewise offered a MOP to reduce all together the total cost, unmet insert and pollutant emissions. For this job, differential development algorithm methods possess been lately utilized to discover the greatest mixture of parts and control tactics for the HRES. The decision parameters, health as well as constraints will beidentified in the PSO algorithm [30]. Style aspects that will be the capability among the components will be outlined in avector called particle. In additional term, every particle signifies a particular construction of the HRES. Total price which is usually an action of style variables is usually regarded as the conditioning of allergens to get debris analysis. Nevertheless, in remote control spaces where the grid extension is usually not really possible, HRESs are being used in the standalone setting pertaining to specific homes and in micro grids (MGs) where many houses will be linked to type a little vitality grid [31]. The second approach is usually getting well-known in destinations and outlying areas it gives a cost-effective option just where effectiveness grid extensions is usually costly as well as, petrol transportation is usually hard and expensive. Presently, the populace in islands is usually approximated to become through 510 million world-wide centered upon geographic information system (GIS) evaluation. An alternative research offers demonstrated which usually various countries dedicate up to $20 \%$ among their gross domestic product (GDP) on standard strength assets, many of these as fossil gasoline or diesel [32]. Sensitivity analysis is definitely the analysis of how feasible variance of the insight variables may affect the ideal answer offered through the marketing algorithm within a provided collection of presumptions. In a sensitivity evaluation, the ideals of details or inputs will be transformed and the lead adjustments in overall performance indices will be assessed. Consequently, a primary objective of a sensitivity analysis can be to determine that parameters are usually the just about all delicate as well as most likely to impact system habit [33].

\section{RESEARCH METHODOLOGY}

Existing research provided an assessment on arranging, designs, modeling as well as marketing of HRES for standalone applications. Nevertheless, these content articles have got certainly not thoroughly resolved all latest one method, hybrid algorithms and application equipment with a crucial assessment of their shows in dimensions of standalone solar power and wind hybrid systems for remote control aspects and island destinations. Few research include presented a summary among some sizes algorithms as well as talked about the ideal sizes procedure of two HRESs. Likewise, groundwork concentrated just on some sole artificial methods to get standalone and grid-connected applications.

Published By:

Blue Eyes Intelligence Engineering

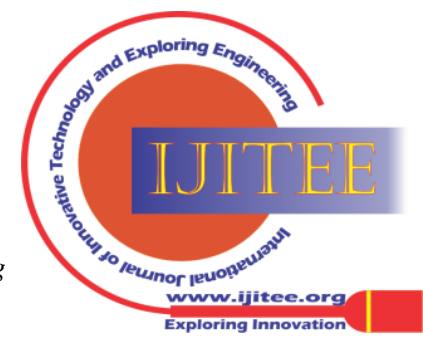


The incorporation of RESs by additional standard energy source resources as well as energy levels storage space devices is usually prevalent in developing hybrid devices to fulfill a provided load marketplace demand.For the case in point, PVWTHS mixture gives even more dependable electricity for off-grid and standalone applications likened to specific programs.

to determine the result ability of WT, Hydro streams and PV mixture. HRES needs to fulfill the load wants in each time period stage. Electrical, cold weather, and hydrogen loads are patterned in HOMER. Electric loads will be main as well as deferrable loads. Main loads happen to be the electric powered load that must end up being achieved in particular time, though deferrable load is usually the electrical power load that needs to get attained among some period time, however, the precise time is in no way essential

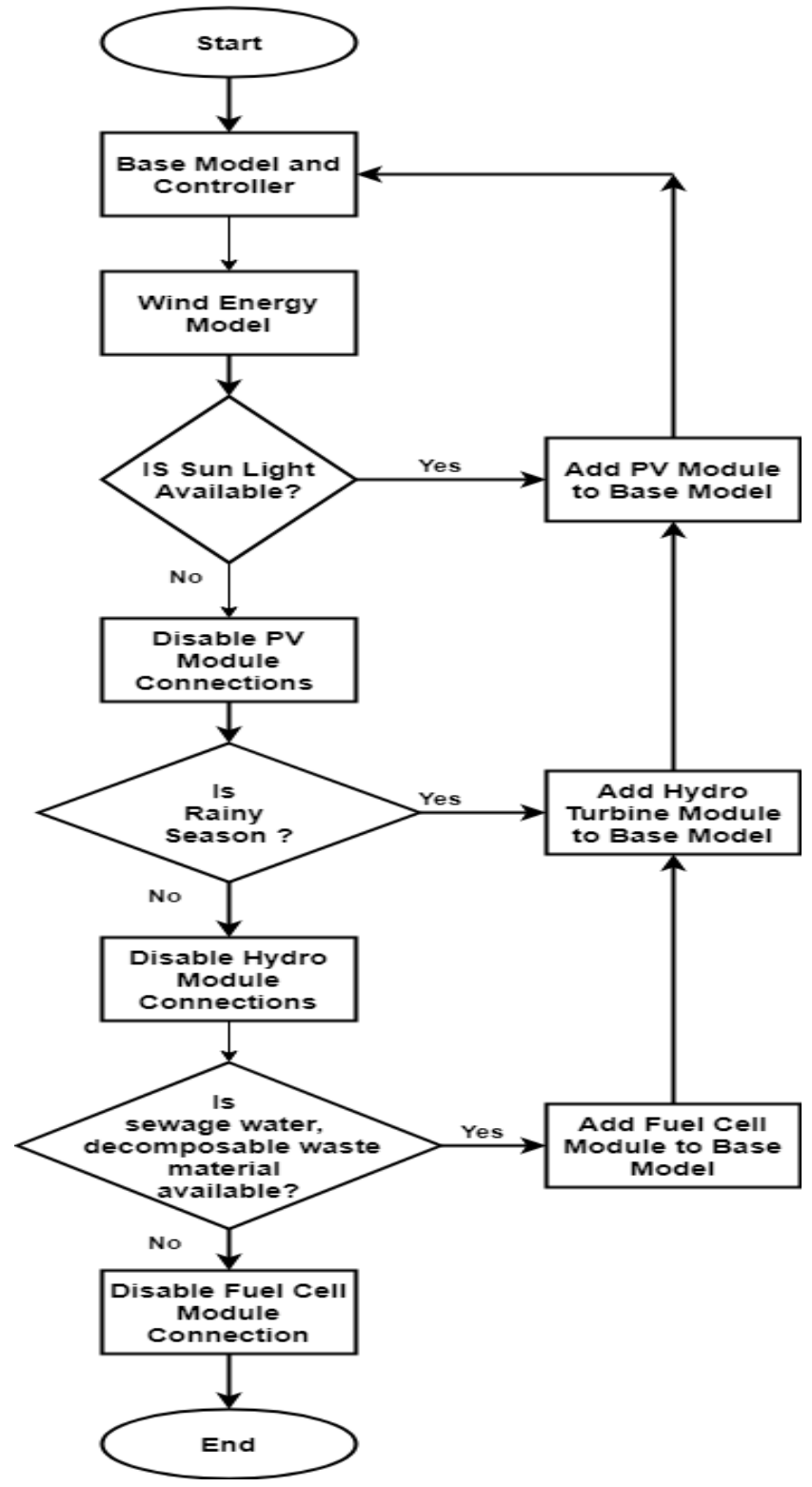

Figure 1: Proposed Methodology

\section{PROPOSED RODE MODEL ALGORITHM}

Input: Plant codes, season code, $\mathrm{CO} 2, \mathrm{CH}_{4}, \mathrm{~N}_{2} \mathrm{O}$ readings

1. Array plantNo[];

2. Array plantType[];

3. Array seasonCode[];

Retrieval Number: 100.1/ijitee.K948609101121

DOI: 10.35940/ijitee.K9486.09101121

Journal Website: www.ijitee.org
As a primary research strategy for the proposed study (shown in figure 1 below), the meteorological info regarded as blowing wind velocity, solar power rays, heat, as well as, stream circulation which will be given straight to the computer software in the type of regular monthly averages or period series data. HOMER incorporates these advises info

4. Array arr $\mathrm{CO}[]$;

5. Array arrCH[];

6. Array arrNO[];

7. Array RoseOptimum[];

8. Array RoseDegraded[];

9. If plant $\mathrm{No}$ [X (is optimum)

Then record (plantType [Xt] \&\& seasonCode[]);

10. If $(\operatorname{arrCO}[]>$ optimum) $\|$

(arrCH[])\|(arrNO[])Then

RoseDegraded[]==true;

Else RoseOptimum[] == true;

11. Go to

Step 7;

12.End

The proposed model intended for connecting appropriate seasonal/weather condition module (like wind, PV, hydro, MFC) to base model. The base model is a collection of units like controllers, transformers, converters and relays etc to add or remove the plant from base model. The experimentalanalysis for proposed rose model for carbon foot printing is discussed in section 4 and 5 of this paper.

\section{CARBON FOOT PRINTING ANALYTICS}

The strategy among carbon foot printing provides permeated and is usually getting released in all the aspects of lifestyle as well as overall economy however, there can be small coherence in meanings and data of carbon foot prints amid the analyses. There will be arguments in the assortment among gas, as well as the purchase of exhausts to get protected in impact information. Requirements among green house gas accounting will be the regular assets utilized in footprint car loans calculations, nevertheless there is certainly no required supply of impact confirmation. Co2 foot printing is normally meant to come to be a device to lead the focused release slashes and verifications, its standardization at worldwide level are consequently required [34]. Relating to this notion, carbon footprint relates to the property region needed to absorb the whole CO2 created through the human beings while its lifetime. In a credited program of period as the global warming up concern required dominance in the globe external plan, utilization of carbon impact started to be widespread individually, although in an altered type [35]. The theory of carbon foot printing features been lately in make use of since many years but regarded in a different way as personal life cycle effect categories signal world-wide heating up probable. Consequently, the present type of carbon footprint may stay seen as a hybrid, deriving its brand from "ecological footprint", as well as, conceptually staying a world-wide increased temperatures probable warning. There will be few studies that statement carbon impact when it comes to global hectares in spite of the contemporary nexus approximately it.

Published By:

Blue Eyes Intelligence Engineering and Sciences Publication

(C) Copyright: All rights reserved.

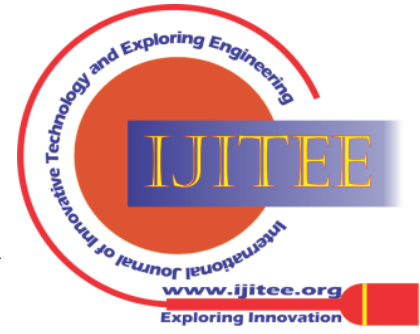


Rather than its common beneficial public status as a pointer among contributing of an organization to the world-wide warming, there happens to be perturbation over what it precisely means. For computing carbon impact, the quantity of GHGs spewed/removed or perhaps put in life cycle of the product needs to be approximated as well as increased. Life cycle contains all the levels included for a product many of these as its produce ideal via getting among natural materials to final product packaging, circulation, intake, and also to the last periods of removal. Evaluation among life cycle therefore is usually likewise referred to as 'holder to plot studies [36]. Life cycle assessment (LCA) generates total photo of advises and results by value to generation of air flow contaminants, water make use of as well as sewage generation, energy ingestion, GHGs imparted, and any additional comparable parameter of curiosity and costbenefit endeavors. This assessment is normally named as external LCA [37]. For carbon foot printing goal, LCA quotes the GHGs emitted/embodied at every recognized stage of the product's life cycle, theoretically regarded as GHG accounting. Requirements as well as guidance will be obtainable to get GHG accounting. Minimizing carbon emission offers been lately a vital concentrate, therefore LCA as an around the globe standardized method is usually broadly used in recent sectors. It quantifies all focused exhausts as well as assets used and so the affiliated external and wellness affects as well as source exhaustion problems that will be connected with items. The International Organization for Standardization (ISO) 14040 and 14044 requirements gives an essential platform pertaining to LCA [38]. Relating to the software in properties centered on LCA, various research possess recognized the general effect of the building of complexes on the setting, and the evaluation goals as well as results will be incredibly diverse. To test the proposed model, we developed MPPT system to identify carbon foot printing and hybrid energy generation units. The control circuit is shown in figure 2 below. Micro-controller is competent to function up to $72 \mathrm{MHz}$ clock frequency. STM functions in Poor power, Sleep, Stop as well as Standby modes. Micro-controller is developing tandem 12bit analog to digital converter with 16 signals, with Dualsample and maintain capabilities. Amplifier signal is with RC low pass filter by cutoff frequency of $250 \mathrm{~Hz}$. Output load voltage is noticed by $12 \mathrm{~V}$ sensing transformer to get load voltage feedback as well as manipulated by pot at the input concerning the sensing circuit. It is designed and released through semiconductor. It includes of two in house occurrence paid out, high gain, as well as independent opamps.

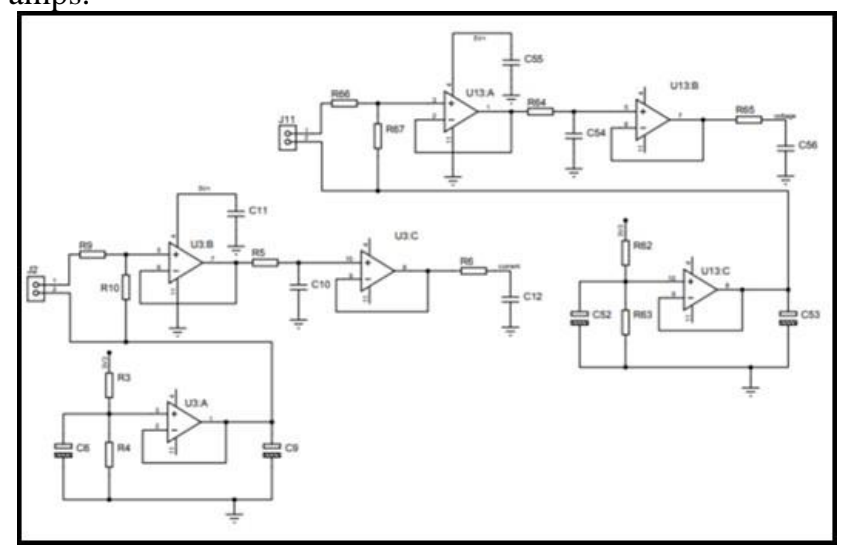

Figure 2: Proposed controller circuit
This carbon computation system steps the greenhouse gas effects of building actions when it comes to carbon dioxide equivalency (CO2e). It will this through determining the put Co2e of components additionally the Co2e connected by their transport. It likewise views gear utilized as well as waste materials removal administration. The driver circuit is usually demonstrated in figure 3 beneath.

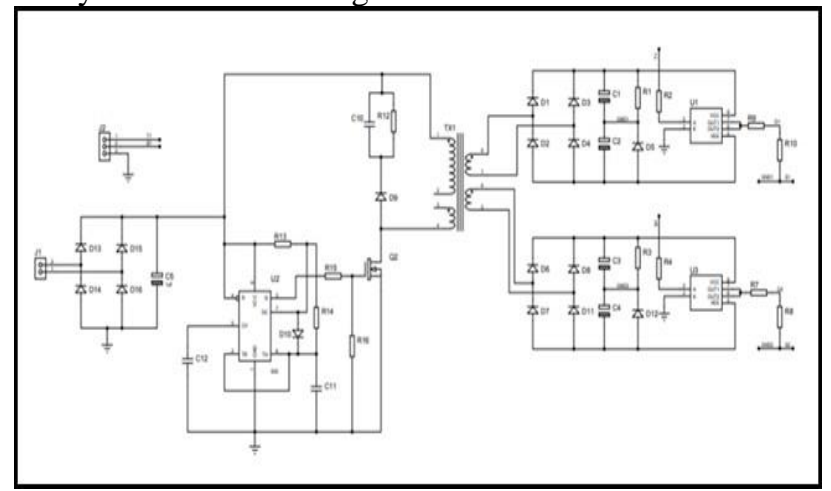

Figure 3: Proposed driver circuit

This system can be utilized to evaluate and evaluate the durability overall performance of diverse design and style, as well as administration options at the layout level. It assists to emphasize where you can help to make better carbon price savings upon particular structure tasks. It may also be utilized to support determine the end users' total carbon release via development and determine aspects recognizing greater discounts. It also adds to the all round emissions as well as quantification in the benefits by carbon dioxide exhausts.

\section{EXPERIMENTAL EXECUTION}

To develop LCA using proposed rose model, we used GaBi-4 [39] software simulation. The input for the system is recorded plant values and sequence of plant operation based on optimum weather conditions. The simulation is executed to identify the proposed system performance over existing Monte Carlo analysis.

To identify carbon foot printing it is necessary to execute rosemodel for LCA.

The direct energy emission can be calculated using rose model as:

$\mathrm{CO}_{2}=\left(\mathrm{T} *\left(\mathrm{CO}_{2} \mathrm{Ef} * \mathrm{Hv} / \mathrm{h}\right) * \mathrm{~d}\right)$

$\mathrm{CH}_{4}=\left(\left(\mathrm{T} *\left(\mathrm{CO}_{2} \mathrm{Ef} * \mathrm{Hv} / \mathrm{h}\right) * \mathrm{~d}\right)\right) * \mathrm{GWP} \mathrm{CH}_{4}$ Conversion) $\mathrm{N}_{2} \mathrm{O}=\left(\left(\right.\right.$ Total Amount $*\left(\mathrm{~N}_{2} \mathrm{O}\right.$ Ef $\left.* \mathrm{Hv} / \mathrm{h}\right) *$ d) * GWP $\mathrm{N}_{2} \mathrm{O}$ Conversion)

Where, Total Amount (T), $\mathrm{CO}_{2}$ Emission Factor (CO2Ef), Heating Value/Humidity (Hv/h), Density (d)

We recorded readings for the proposed system for the period June 2019 to June 2020 and simulated usingGaBi4 software. The various GHG parameters are identifiedwhich can be eliminated using proposed rose model analysis for hybrid renewable energy sources. The detailed rose model output is shown in section 6 of this paper. For a detailed analysis, $\mathrm{GaBi}$ offers scenario analysis, parameter variation, and sensitivity analysis. The input is given as a recorded dataset to Gabi for actual plants, and MATLAB simulation is executed to get MPPT. Following circuit in figure 4 shows MPPT simulation.

Published By:

Blue Eyes Intelligence Engineering

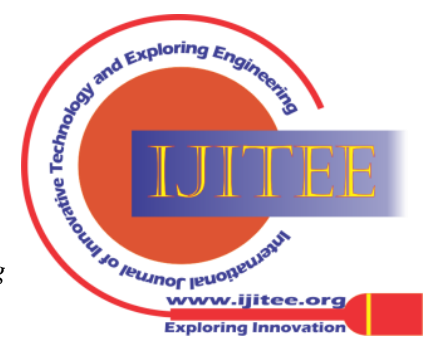


$\mathrm{GaBi}$ is a pointing application for building services as well as programs by a life cycle perception. The individual needs to develop a life-cycle to discover carbon foot printing as demonstrated in figure 5 and 6 below. GaBi software is the corporal procedure that is employed to produce the several general variables.
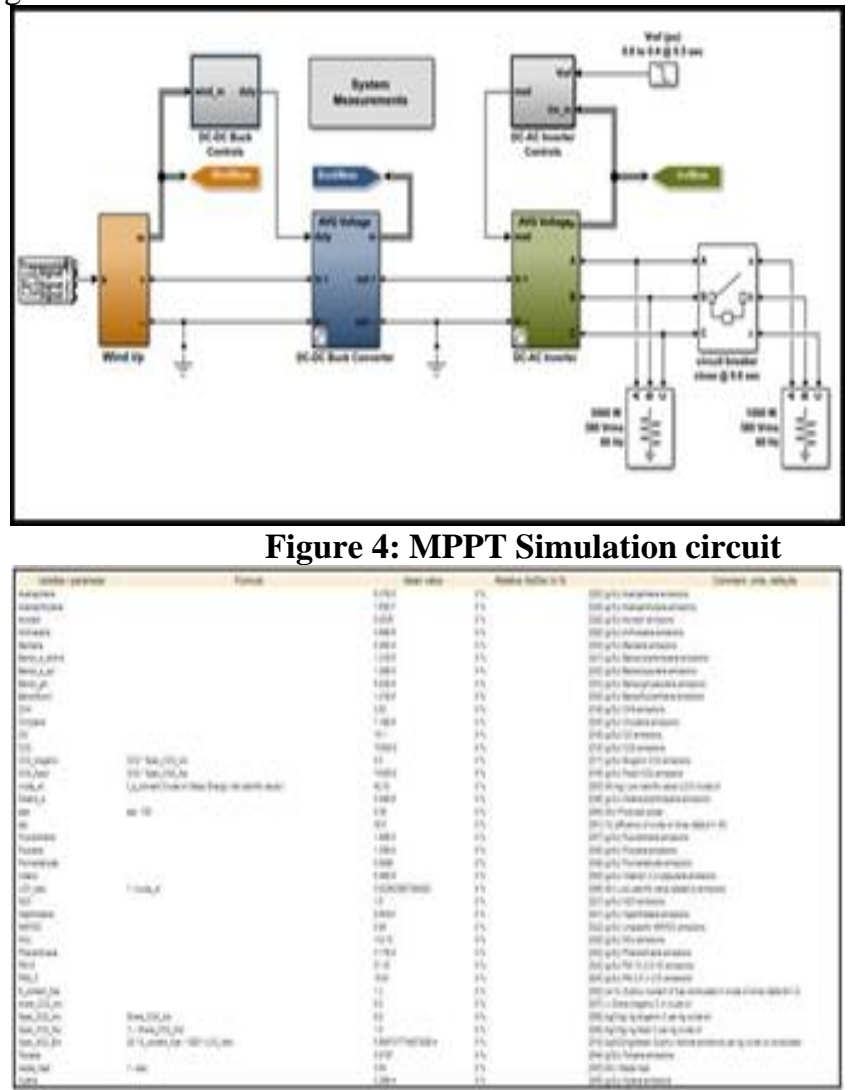

Figure 5: Gabi dataset parameters (Source: Gabi x)

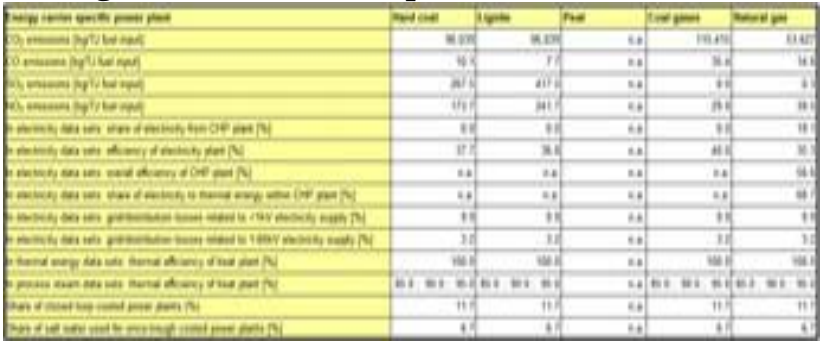

Figure 6: Plant Specific Emission Percentages (Source:

\section{Gabi x)}

Aside from quantitative computation and evaluating the carbon release for diverse development programs, the engineered system also is designed to increase consciousness among the advantages of lasting style for setting up engineering as well as help end users in evaluating the put energy and carbon cost savings that may happen through developing to get build. This can certainly offer a program inthe decision-making procedure as well as encourage carrying on conversation concerning the within celebrations included.

\section{RESULT AND ANALYSIS}

The experimental results are statistically calculated for individual plant unit and represented as per seasonal performance. For wind energy generation figure 7 shows thedirection of wind and its velocity as per particular season or weather conditions.

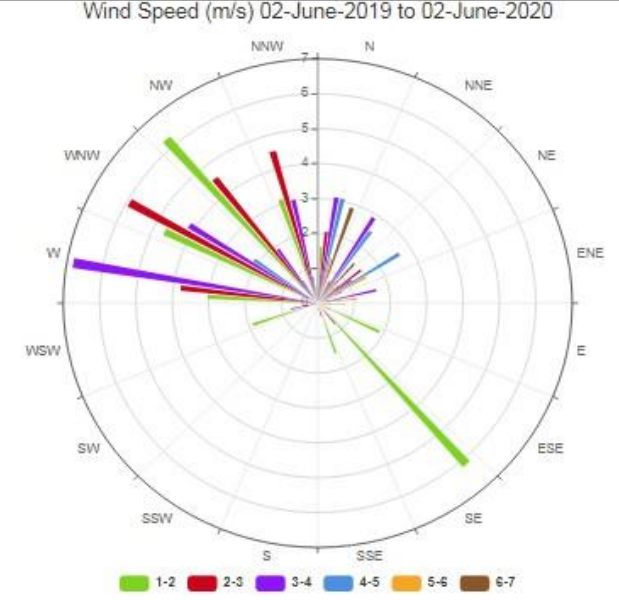

Figure 7: Wind-rose model analysis

Similarly, PV module performance can be higher in summer as compared to rainy and winter season. Hence, figure 8 shows the performance for temperature T9 to T12 as high performance

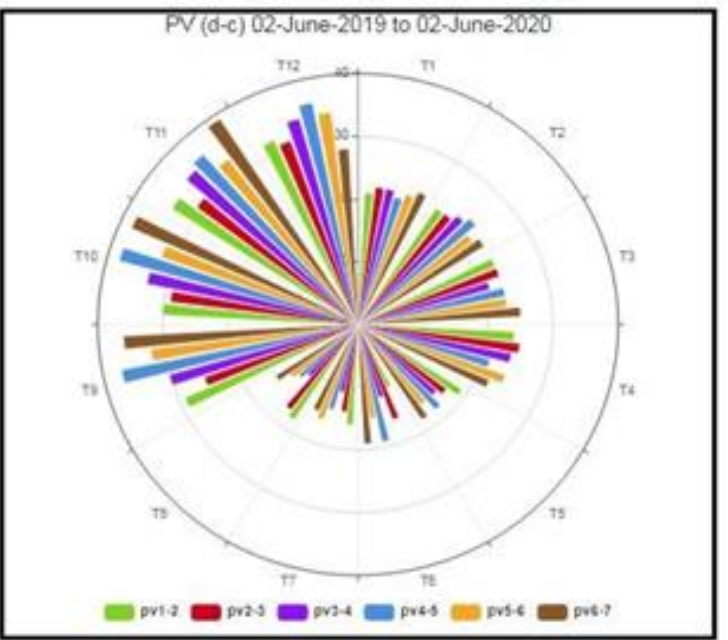

Figure 8: PV-rose model analysis

The hydro streams can be called as pico hydro energy generation which can be executed in hilly area to get benefit of small water fall/stream with collective force which can drive the turbines. Figure 9 shows the performance of rose model

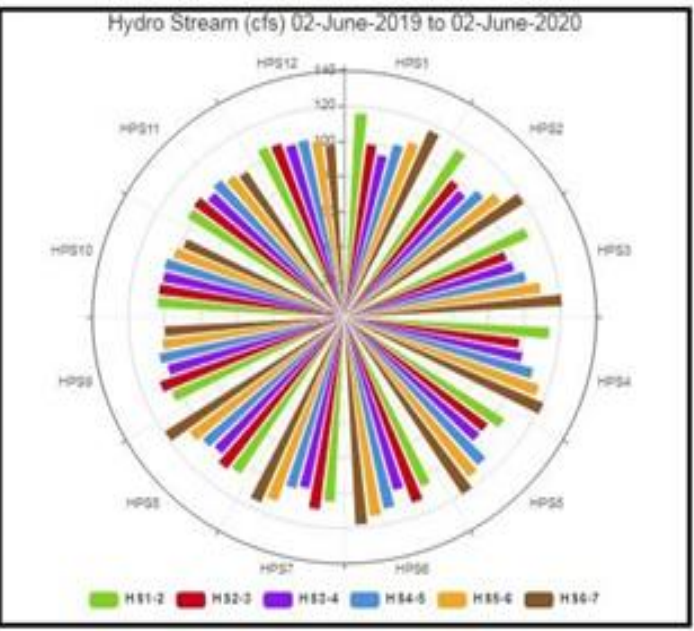

Figure 9: Hydro stream-rose model analysis Copyright. All rights reserved.

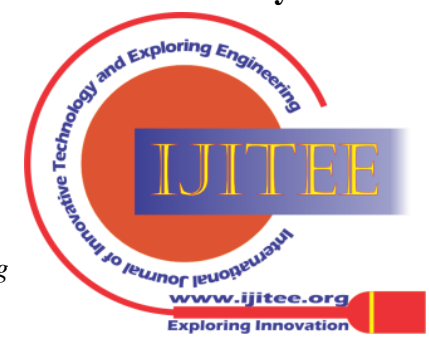




\section{Development of Rose Model for Hybrid Renewable Energy Generation and Analysis of Carbon Foot Printing QOS Parameters}

The proposed rose model development can be efficient as compared to Monte Carlo analysis as instead of statistical analysis proposed rose model can be used to identify plant specific performance and carbon foot printing ratio

\section{CONCLUSIONS}

1. Boost of the world-wide energy marketplace demand as well as geographical complications relating to fossil energy usage possess advertised the common study on green energy systems to change the classicprecious energy sources.

2. Especially, hybrid devices that may become described as a mixture among sustainable and backup models and standard energy resources turninto a relevant answer to the difficulties which usually the globe encounters at this time to get durability concern concerning energy source as well as green safety.

3. The proposed rose model analysis revealed that developed

simulation system and actual system can provide minimum carbon foot printing with optimum MPPT performance.

4. The proposed automatic scheduler algorithm helps to improve the wind energy, PV and hydro stream functioning based on climatic conditions. Such a system can be used for small capacity power generation for individual household use or rural electrification.

\section{REFERENCES}

1. Sarkodie, Samuel Asumadu. "Environmental performance, biocapacity, carbon \& ecological footprint of nations: Drivers, trends and mitigation options." Science of the Total Environment 751 (2020): 141912

2. Kaldellis, J. K., and D. Apostolou. "Life cycle energy and carbon footprint of offshore wind energy. Comparison with onshore counterpart." Renewable Energy 108 (2017): 72-84.

3. Gamarra, A. R., et al. "Energy and water consumption and carbon footprint of school buildings in hot climate conditions. Results from life cycle assessment." Journal of Cleaner Production 195 (2018): 1326-1337.

4. Artz, Jens, et al. "Sustainable conversion of carbon dioxide: an integrated review of catalysis and life cycle assessment." Chemical reviews 118.2 (2018): 434-504.

5. Bartolozzi, Irene, Francesco Rizzi, and Marco Frey. "Are district heating systems and renewable energy sources always an environmental win-win solution? A life cycle assessment case study in Tuscany, Italy." Renewable and Sustainable Energy Reviews 80 (2017): 408-420.

6. Valente, Antonio, Diego Iribarren, and Javier Dufour. "Harmonised life-cycle global warming impact of renewablehydrogen." Journal of Cleaner Production 149 (2017): 762-772.

7. Mälkki, Helena, and Kari Alanne. "An overview of life cycle assessment (LCA) and research-based teaching in renewable and sustainable energy education." Renewable and Sustainable Energy Reviews 69 (2017): 218-231.

8. Vares, Sirje, et al. "Impact of renewable energy technologies on the embodied and operational GHG emissions of a nearly zero energy building." Journal of Building Engineering 22 (2019): 439-450.

9. El-Aasar, Khadiga Mohamed, and Shaimaa A. Hanafy. "Investigating the environmental Kuznets curve hypothesis in Egypt: the role of renewable energy and trade in mitigating GHGs." International Journal of Energy Economics and Policy 8.3

10. Ottelin, Juudit, JukkaHeinonen, and SeppoJunnila. "Carbon footprint trends of metropolitan residents in Finland: how strong mitigation policies affect different urban zones." Journal of Cleaner Production 170 (2018): 1523-1535. (2018): 177-184.

11. Sethi, Mahendra. Climate change and urban settlements: A spatial perspective of carbon footprint and beyond. Taylor \& Francis, 2017.

12. Chernova, Nadezhda I., Sophia V. Kiseleva, and Mikhail S. Vlaskin. "Biofuel production from microalgae by means of hydrothermal liquefaction: advantages and issues of the promising method." International Journal of Energy for a Clean Environment 18.2 (2017).

13. Hong, Jingmin, et al. "Life-cycle environmental and economic assessment of medical waste treatment." Journal of cleaner production 174 (2018): 65-73.

14. Ludin, Norasikin Ahmad, et al. "Prospects of life cycle assessmentof renewable energy from solar photovoltaic technologies: a review." Renewable and Sustainable Energy Reviews 96 (2018):11-28.

15. Akyüz, Mehmet Kadri, HaşimKafalı, and ÖnderAltuntaş. "An analysis on energy performance indicator and GWP at Airports; a case study." Energy Sources, Part A: Recovery, Utilization, and Environmental Effects (2020): 1-17.

16. Zhang, Cheng, et al. "Energetic, exergetic, economic and environmental (4E) analysis and multi-factor evaluation method of low GWP fluids in trans-critical organic Rankine cycles." Energy 168 (2019): 332-345.

17. Ghimire, Sujan, et al. "Global solar radiation prediction by ANN integrated with European Centre for medium range weather forecast fields in solar rich cities of Queensland Australia." Journal of cleaner production 216 (2019): 288-310.

18. Jurasz, Jakub, AlexandreBeluco, and Fausto A. Canales. "The impact of complementarity on power supply reliability of small scale hybrid energy systems." Energy 161 (2018): 737-743.

19. Tezer, Tuba, RamazanYaman, and GülșenYaman. "Evaluation of approaches used for optimization of stand-alone hybrid renewable energy systems." Renewable and Sustainable Energy Reviews 73 (2017): 840-853.

20. Eriksson, E. L. V., and E. MacAGray. "Optimization and integration of hybrid renewable energy hydrogen fuel cell energy systems-A critical review." Applied energy 202 (2017): 348-364.

21. Goel, Sonali, and Renu Sharma. "Performance evaluation of stand alone, grid connected and hybrid renewable energy systems for rural application: A comparative review." Renewable and Sustainable Energy Reviews 78 (2017): 1378-1389.

22. Mokhtara, Charafeddine, et al. "Integrated supply-demand energy management for optimal design of off-grid hybrid renewable energy systems for residential electrification in arid climates." Energy Conversion and Management 221 (2020): 113192.

23. GOUD, B. SRIKANTH, and Ch Rami Reddy. "Essentials for Grid Integration of Hybrid Renewable Energy Systems: A Brief Review." International Journal of Renewable Energy Research (IJRER) 10.2 (2020): 813-830.

24. Li, Xiaozhu, et al. "Dynamic environmental economic dispatch of hybrid renewable energy systems based on tradable green certificates." Energy 193 (2020): 116699.

25. ANI, VINCENT. "Strategies for Modeling and Simulation of Alternative Energy Systems for Powering Health Clinic at Various Geographical Locations Using HOMER Software." (2020).

26. Aly, Abdelmaged M., et al. "Design of microgrid with flywheel energy storage system using HOMER software for case study." 2019 International Conference on Innovative Trends in Computer Engineering (ITCE). IEEE, 2019.

27. Ben Messaoud, Ramzi. "Extraction of Uncertain Parameters of Double-Diode Model of a Photovoltaic Panel Using Simulated Annealing Optimization." The Journal of Physical Chemistry C 123.48 (2019): 29096-29103.

28. Chen, Min-Rong, Guo-QiangZeng, and Kang-Di Lu. "Constrained multi-objective population extremal optimization based economicemission dispatch incorporating renewable energy resources." Renewable Energy 143 (2019): 277-294.

29. Guenounou, Ouahib, BoutaibDahhou, and FerhatChabour."Multiobjective optimization of fuzzy MPPT using improved strength Pareto evolutionary algorithm." 2020 International Conference on Electrical, Communication, and Computer Engineering (ICECCE). IEEE, 2020.

30. Singh, Poonam, ManjareePandit, and LaxmiSrivastava. "PSO-Based Optimization of Levelized Cost of Energy for Hybrid Renewable Energy System." Nature Inspired Optimization for Electrical Power System. Springer, Singapore, 2020. 31-42.

Published By:

Blue Eyes Intelligence Engineering

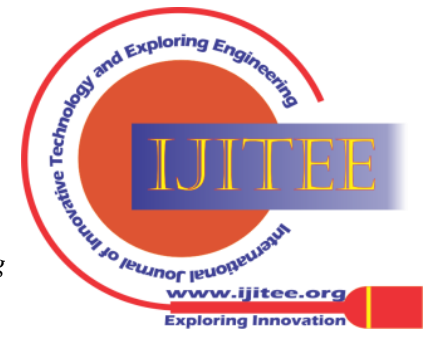


31. Bhattacharjee, Somudeep, and Champa Nandi. "Design of a voting based smart energy management system of the renewable energy based hybrid energy system for a small community." Energy 214 (2020): 118977.

32. Settou, Belkhir, et al. "A high-resolution geographic information system-analytical hierarchy process-based method for solar PV power plant site selection: a case study Algeria." Clean Technologies and Environmental Policy (2020): 1-16.

33. Agyekum, Ephraim Bonah, and ChristabelNutakor. "Feasibility study and economic analysis of stand-alone hybrid energy system for southern Ghana." Sustainable Energy Technologies and Assessments 39 (2020): 100695.

34. Chen, Shaoqing, et al. "Advanced approaches and applications of energy footprints toward the promotion of global sustainability." (2020): 114415.

35. Ladenika, A. O., et al. "The availability of life-cycle assessment, water footprinting, and carbon footprinting studies in Brazil." International Journal of Life Cycle Assessment 23.8 (2018).

36. Islam, MdShamimul, et al. "Renewable Energy Aware Cost Assessment for Green Data Center with Hybrid Energy Sources." 2019 International Conference on Robotics, Electrical and Signal Processing Techniques (ICREST). IEEE, 2019.

37. Bahlawan, Hilal, et al. "Optimization of a hybrid energy plant by integrating the cumulative energy demand." Applied Energy 253 (2019): 113484

38. Marques, Adriano da S., et al. "Life cycle assessment and comparative exergoenvironmental evaluation of a micro-trigeneration system." Energy (2020): 119310.

39. Silva, DiogoAparecido Lopes, et al. "Why using different Life Cycle Assessment software tools can generate different results for the same product system? A cause-effect analysis of the problem." Sustainable Production and Consumption 20 (2019): 304-315.

\section{AUTHORS PROFILE}

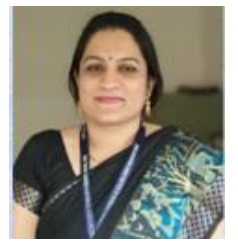

Carbon footprints

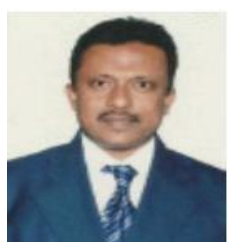

Mrs. Manjusha Sham Patil, has 13 years of experience in teaching, She is $\mathrm{PhD}$ Scholar in Electrical Engineering at JJTU .She has done B.E. (Electrical Engineering) from K K Wagh college of Engg. Nashik (India) and M.E. (Power Electronics and Drives) from AISSMS College of Engineering Pune. Her research interests include Power electronics, hybrid renewable energy sources, and

Dr. Anwar. Mubarak. Mulla has 22 years of experience in teaching. He is Ph.D. in Electrical Engineering. He has done B.E. (Electrical Engineering) from Government college of Engg. Karad (In dia), and M.E. (Electrical Power systems) from Walchand College of Engineering Sangli. His research interests include High Voltage Engg, Renewable Energy sources and Applications, Wind Power Generation, Instrumentation and control. He has published 10 research papers in reputedInternational/National Journals/Conferences. Presently he is working as Principal, at Annasaheb Dange College of Engineering and Technology, Ashta, India
Published By: Blue Eyes Intelligence Engineering and Sciences Publication (C) Copyright: All rights reserved.

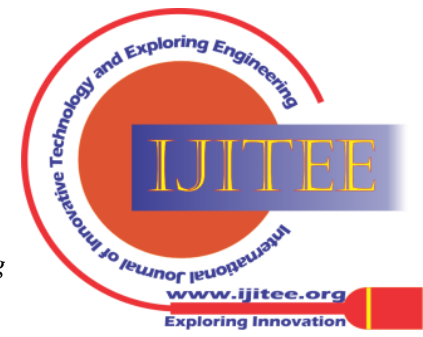

